\title{
Fused Deposition Modeling Technology to Redesign a Nylon Component
}

\begin{abstract}
NICOLETA ELISABETA PASCU1', TIBERIU DOBRESCU2*, ADRIAN POPESCU², VICTOR GABRIEL ADIR ${ }^{1}$
'University Politehnica of Bucharest, Department of Engineering Graphics and Industrial Design, 313 Splaiul Independenpei, 060042, Bucharest, Romania

ZUniversity Politehnica of Bucharest, Department of Machine and Manufacturing Systems, 313 Splaiul Independenpei, 060042, Bucharest, Romania

3D printing by means of the Fused Deposition Modeling technology allows to obtain accurately and with very good results, plastic parts with various, simple or complex typo-dimensions and forms. The part in this article is from the field of road vehicles, it is called fixing clamp and it is of average complexity of the hole strip type with two protuberances necessary to ensure the purpose for which they provided. The necessity of making the part through addition appeared because it is not the market and because it was not provided by the supplier [1]. The constructive solution offered by the producer is a very good and necessary one, in the same time for the user in the equipment in which it is included (fig. 10). The constructive solution proposed in this article resulted from tests on some parts of Acrylonitrile-Butadiene-Styrene and Nylon and the results were conclusive for choosing and adopting the Nylon variant.
\end{abstract}

Keywords: 3D printing, Fused Deposition Modeling, Acrylonitrile-Butadiene-Styrene, Nylon, fixing clamp

Additive manufacturing or Addition manufacturing has as basic principle to make a model (generated by a computer - 3D CAD), which can be manufactured directly without the need for planning the manufacturing process. This technology simplifies significantly the productions of complex objects directly from CAD virtual models undergoing transfer processes from a software to another before returning to the machine tool that makes it (the 3D printer). The traditional manufacturing processes require a detailed and thorough knowledge of the following: the geometry of the piece to determine the order of the manufacturing operations; the multiple and different technological processes used to obtain the piece and, also, the necessary tools and machine tools. Additive manufacturing requires details on the basic dimensions of the piece, on understanding how the 3D printer works, the way in which the piece is constructed and the materials that are used in the process.

The additive manufacturing technological process is briefly described in figure 1[2].

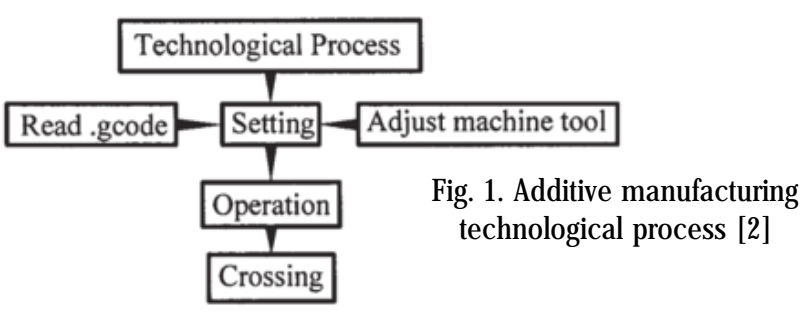

Experimental part

Materials and methods

The printing process (fig. 2) consists of forcing the plastic material (5) fused into a tank (2) to pass through a nozzle (7) when a constant pressure is applied. The resulting extruded material will flow at a constant speed and will have the same cross-sectional diameter. Moving the flow nozzle on the deposition surface (6) is also maintained at a constant speed thus resulting in a constant flow of deposition. Since the material is extruded on a platform, the print head (1) can go through the work surface in a

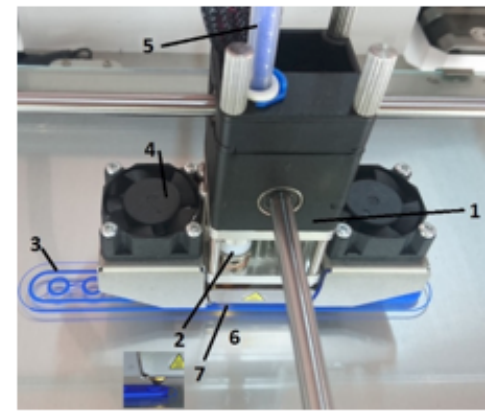

Fig. 2. FDM Printing $[4,5]$

horizontal plane and determine the start and stop of the material flow during the crossings [3]. Once a layer (3) is completed, the piece goes down vertically- the Z-axis so that an additional layer can be deposited. The fans (4) mounted on the sides of the print head ensure the solidification of the layers, one upon the other.

The materials available for this kind of printing are on the market in a wide variety but for the experimental part we used Acrylonitrile-Butadiene-Styrene and Nylon. The filament of Acrylonitrile-Butadiene-Styrene used has the following characteristics: blue filament diameter of $2.85 \pm 0.10 \mathrm{~mm}$, product code RAL 500 provided by Ultimaker [4]. The extrusion temperature in the experimental parts was of $250^{\circ} \mathrm{C}$ for the nozzle temperature and of $80^{\circ} \mathrm{C}$ for the build plate temperature, while the extrusion speed was kept at $120 \mathrm{~mm} / \mathrm{s}$. The characteristics of the Nylon filament used are the following: transparent filament diameter of $2.85 \pm 0.05 \mathrm{~mm}$, product code $\mathrm{n} / \mathrm{a}$ provided by Ultimaker [4]. The extrusion temperature in the experimental parts was of $250^{\circ} \mathrm{C}$ for the nozzle temperature and of $60^{\circ} \mathrm{C}$ for the build plate temperature, while the extrusion speed was kept at $120 \mathrm{~mm} / \mathrm{s}$.

The 3D printed parts were made in XY plane using a normal printing profile in Cura 2.3.0 and a 3D Ultimaker 2+ printer with a printing nozzle of $0.4 \mathrm{~mm}$ in diameter and a filling density of the part of $100 \%$.

For both sets of tests we used the following characteristics of the printing process (table 1). 


\begin{tabular}{|l|l|l|}
\hline Parameter & $\begin{array}{l}\text { Acrylonitrile- } \\
\text { Butadiene-Styrene }\end{array}$ & Nylon \\
\hline Nozzle & $0.4[\mathrm{~mm}]$ & $0.4[\mathrm{~mm}]$ \\
\hline Layer Height & $0.15[\mathrm{~mm}]$ & $0.15[\mathrm{~mm}]$ \\
\hline Profile & Normal & Normal \\
\hline Wall Thickness & $1[\mathrm{~mm}]$ & $1[\mathrm{~mm}]$ \\
\hline Top/Bottom Thickness & $1[\mathrm{~mm}]$ & $1[\mathrm{~mm}]$ \\
\hline Infill Density & $100 \%$ & $100 \%$ \\
\hline Print Speed & $120[\mathrm{~mm} / \mathrm{s}]$ & $120[\mathrm{~mm} / \mathrm{s}]$ \\
\hline Travel Speed & $150[\mathrm{~mm} / \mathrm{s}]$ & $150[\mathrm{~mm} / \mathrm{s}]$ \\
\hline Support Placement & Everywhere & Everywhere \\
\hline Build Plate Adhesion Type & Skirt & Skirt \\
\hline
\end{tabular}

Table 1

CHARACTERISTICS OF THE PRINTING PROCESS

\section{Results and discussions}

After analyzing the possibilities of obtaining the part through addition, as shown in figure $3 a$ (which presents the model in the original constructive version) we found it unable to obtain through this technology the entire piece as it was originally designed therefore we adopted constructive variants for redesign the part by decomposing the form into two distinct components that will be made through addition without encountering any construction problems. After their physical obtaining through 3D printing by the Fused Deposition Modeling technology [13], in the stage called componentassembly, we will obtain the same product that will meet the conditions of precision and safety in accordance with the standards required. Variant a) in figure 3 cannot be positioned on the printing machine because the making (execution) in console without construction support is impossible. Constructing a supporting device on the entire length of the clip involves unnecessary material consumption. For variant b) in figure 3 the construction of the support device is removed, since the pieces are made directly on the construction platform of the machine.
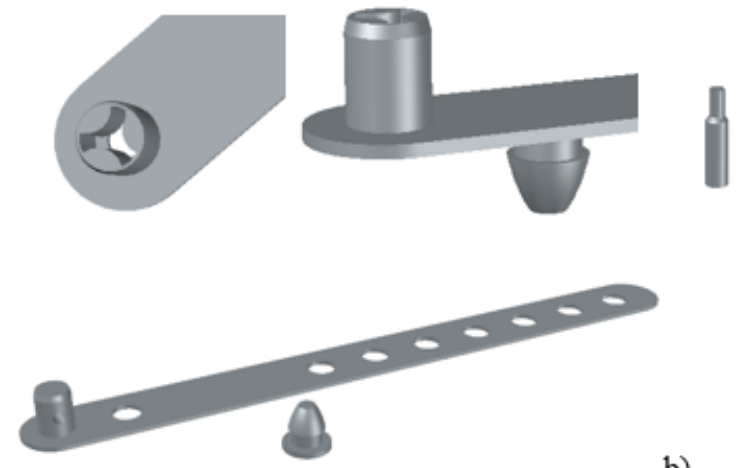

b)

Fig. 3. 3D Models (original variant - $a$, and redesigned variant- b)

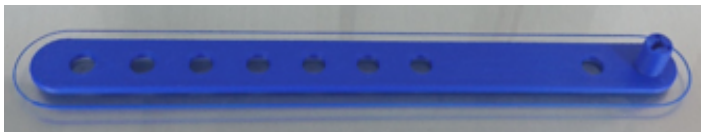

Fig. 4. Printed fixing clamp of Acrylonitrile-Butadiene-Styrene

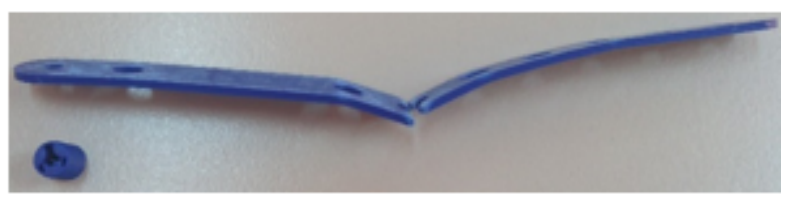

Fig. 5. Damaged fixing clamp

In the first phase of the tests we made the fixing clamp, with the initial form of the fixing element, of AcrylonitrileButadiene-Styrene (fig. 4). Following the mechanical stress (a material with relatively high rigidity), the clamp strip cracked after bending and the protuberance afferent to the fixing element broke. The protuberance wall is of 0.5 $\mathrm{mm}$ (fig. 5) [6]. After this test, we renounced using the material, since the result is conclusive.

In the second phase of the tests, we kept the constructive forms and replaced the AcrylonitrileButadiene-Styrene with Nylon, the clamp collar having a thickness of $1 \mathrm{~mm}$ after repeated bending with high frequency, did not break and did not crack, yet, presented signs of bending on the area subjected to folding. In this case, also, the fixing element of the clamp broke (fig. 6).

Printing the fixing stud (fig. 7) is impossible because its maximum diameter is of $3 \mathrm{~mm}$. It can be printed with an appropriate precision if a support is constructed around it, and this support will be removed in a subsequent cleaning operation.

Printing the coupling element of the clip (fig. 8) did not pose problems, it but required a supporting device around the protuberance. After successive tests, we determined a maximum height of $3 \mathrm{~mm}$ of the support. A height greater

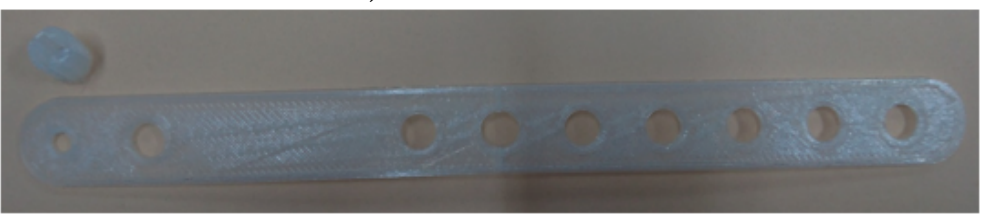

Fig. 6. Fixing clamp, the original variant of damaged nylon 


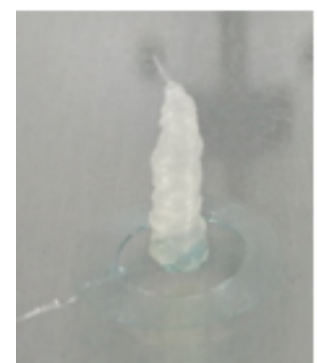

Fig. 7. Fixing Stud

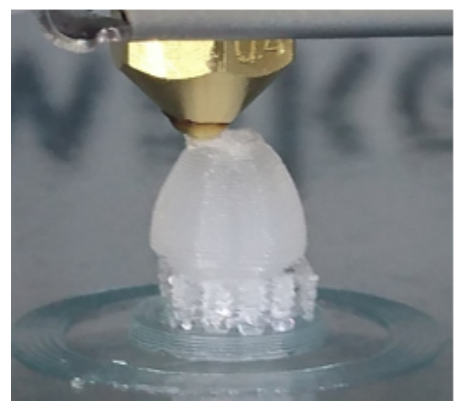

Fig. 8. Grip protuberance

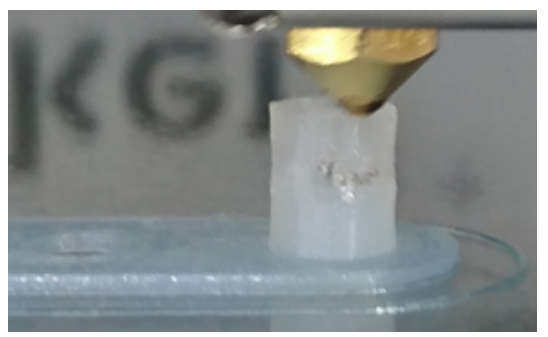

Fig. 9. Printing the fixing clamp, modified constructive variant
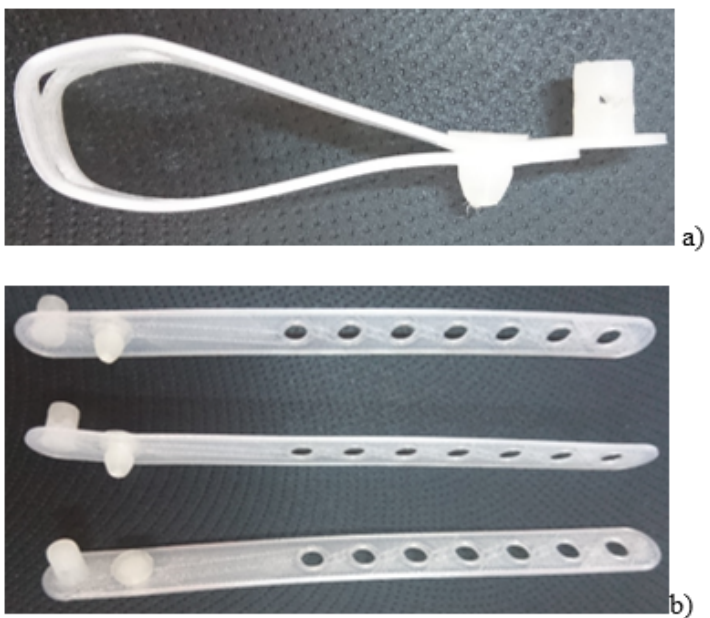

Fig. 10. Fixing clamp with the clip dimension of $0.8 \mathrm{~mm}$

than $3 \mathrm{~mm}$ causes the deposited layers to break reducing its resistance (cleavage occurs betw een layers). The parts modeling was performed in a CAD program that allows the generation of the surfaces at a resolution compatible with obtaining high accuracy geometric forms (flat surface) $[7,8]$. Separate module design lends itself to 3D printing $[9,10]$. We mention thatone cannotobtain high complexity pieces without support constructions [11]. These support constructions raise the cost of manufacturing by material loss. It is therefore preferable to eliminate them.

In the next stage of testing we changed the form of the fixing clamp. After the tests, we opted for a filled cylinder of $6 \mathrm{~mm}$ diameter with a cylindrical hole whose axis is perpendicular to the fixing cylinder axis of $2 \mathrm{~mm}$ in diameter (fig. 9), its axis being at $3 \mathrm{~mm}$ from the full cylinder base. This variant is much more easily to obtain on the FDM 3D printer and its making falls within precise dimensional tolerances.

In the final stage of testing, aiming for a higher flexibility, we resorted to reducing the thickness of the fixing clip from $1 \mathrm{~mm}$ (fig. 10) to $0.8 \mathrm{~mm}$ (fig. $10 \mathrm{~b}$ ). This aspect leads to the reduction of material consumption. The results were more than satisfactory in terms of the physical appearance but also in terms of the strength characteristics of the clip compared to the original clip obtained by plastic injection.

In figure 11 it is shown the fixing clamp in the mounting position of the redesigned variant with the form modifications and thinned dimensions for the clip.

For a clearer understanding of using this fixing clamp we show figure 12 (photo image).

This variant of the fixing clamp was made and tested in laboratory conditions, and now it is being tested on a number of cars with volunteering subjects, the clamp not being a vital piece in the proper functioning of a vehicle. The data collected from tested subjects (after some time) will be subject to technical analysis, involving the clamp structure and strength in activity, and will form the basis for completing the practical use stage of the partsubjected to the concept of redesign.

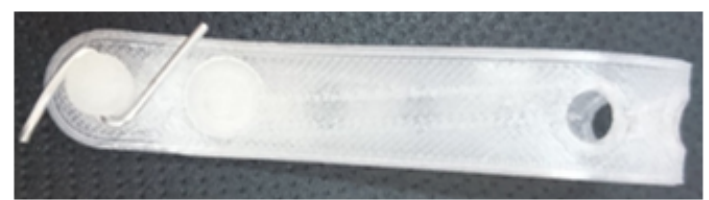

Fig. 11. Mounted position clamp

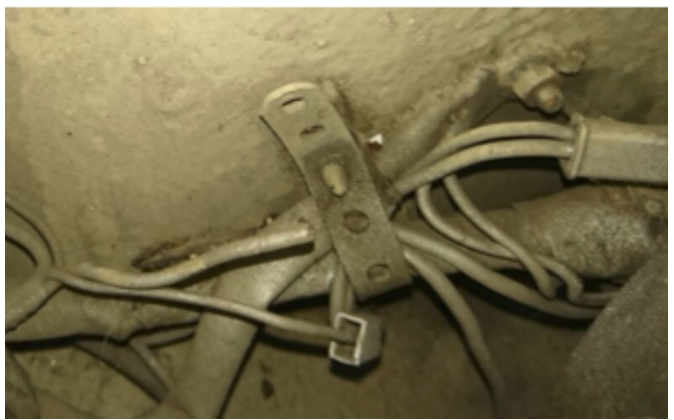

Fig. 12. Mounted clip

\section{Conclusions}

The article highlighted the importance of redesigning a part of Nylon plastic type to be made by using the Fused Deposition Modeling technology, withoutimpeding on the characteristics stipulated by the rules of use. Thus, this example shows the power of both the designer and applied technology to be able to develop similar or improved parts while keeping the functionality characteristics part. We would even dare say, by this example, that this article pleads for the use of 3D printing by means of the Fused Deposition Modeling technology.

As a conclusion of this study, by comparison, there resulted that the variant obtained by plastic injection technology is superior in terms of productivity but not of the parts cost (2 RON for plastic injection at the suppliers). By a simple calculation of the material and energy consumption, along with the support construction, a fixing clamp would cost approx. 0.60 RON.

\section{References}

1. *** http://www.redplast.ro

2. PASCU, N. E., ARION, A.F., DOBRESCU, T., CARUTASU, N.L., Fused Deposition Modeling Design Rules for Plastics, available at: http:// www.revmaterialeplastice.ro, MATERIALE PLASTICE 52, No. 2, pp141143,2015

3. GIBSON, I., ROSEN, D. W., STUCKER, B., Additive Manufacturing Technologies - Rapid Prototyping to Direct Digital Manufacturing, Publisher: Springer, New York, 2010

4. ***Make Ultimate Guide to 3D Printing, available at: http:// web.makezine.com

5. ***Available at: http://web.stratasys.com

6. CARUTASU, N.L., SIMION, I., CARUTASU, G., JIGA, G., ARION, A.F., Experimental Test for Elastic and Mechanical Evaluation of ABS Plastic Used in 3D Printing, available at: http://www.revmaterialeplastice.ro, Mat. Plast., 52, no. 3, 2015, p. 397 
7. ARION, A., DOBRESCU, T.G., PASCU, N.E., 3D surface modelling aspects for 3D printing, Proceedings in Manufacturing Systems, Volume 9, Issue 4, www.icmas.eu, Editura Academiei Române, Bucuresti, p. 199-204, 2014

8. *** available at: http://web.autodesk.com

9. VALTER, N., ANDRONICEANU, A., DRAGULANESCU, I.V., DUCA M.,Agile Management Based On Modularization Of Products And Processes, Proceedings of BASIQ, pp: 310-318. Basiq International Conference: New Trends In Sustainable Business And Consumption, J une 02-03, Konstanz, Germany, 2016

10. VALTER N.,DUCA M., About efficiency of modular designed devices - Journal of Industrial Design and Engineering Graphics, vol 10, Issue No. 1, fascicle 4, pp.17-20, ISSN 1843-3766, 2015
11. POPESCU, D., LAPTOIU, D., HADAR, A. , ILIE, C., PARVU, C., Workflow for additive manufacturing of an individualized surgical template, Proceedings in Manufacturing Systems, Volume 10, Issue 3, 2015

12. SIMION, I., ARION A.F., Dimensioning rules for $3 d$ printed parts using additive technologies (FDM), U.P.B. Sci. Bull., Series D, Vol. 78, Iss. 2, 2016

13. POPESCU, D., HADAR, A., COTET, C.,Manufacturing of ABS P400 Solid Cellular Structures with Closed Cells By Fused Deposition Modeling as Rapid Prototyping Process, Mat. Plast., 43, no. 2, 2006, p. 175

$\overline{\text { Manuscript received: } 14.10 .2016}$ 